\title{
Early-stage clinical outcomes and rotational stability of TECNIS toric intraocular lens implantation in cataract cases with long axial length
}

Suhong $\mathrm{He}^{1,2}$, Xiang Chen ${ }^{1}$, Xingdi Wu${ }^{1}$, Yajuan $\mathrm{Ma}^{1}$, Xuewen $\mathrm{Yu}^{1}$ and Wen Xu ${ }^{1 *}$ (D)

\begin{abstract}
Background: A major focus of toric intraocular lens ( $\mathrm{IOL})$ implantation is the rotational stability, especially in the patients with long axial length (AL). In this study, we aimed to evaluate the clinical outcomes after implantation of TECNIS toric IOL in eyes with long AL and identify factors influencing their early-stage stability with preoperative corneal astigmatism.
\end{abstract}

Methods: The study population consisted of 64 eyes from 52 cataract patients, and these patients had preoperative corneal astigmatism between 1.0 and 3.7 diopters (D) and underwent phacoemulsification and TECNIS toric IOL implantation. Ophthalmic biological measurements were carried out preoperatively, including AL, anterior chamber depth (ACD), lens thickness (LT), vitreous length (VL), anterior chamber volume (ACV), sulcus-to-sulcus (STS) and keratometric value (K). Clinical examinations, including visual acuity, manifest refraction, keratometry, digital anterior segment photographs with pupillary dilation, were performed at 1 and 3 months after surgery.

Results: The mean best corrected distance visual acuity (BCDVA) was improved from $0.93 \pm 0.35$ logarithms of the minimal angle of resolution (logMAR) preoperatively to $0.07 \pm 0.10 \log M A R$ postoperatively at 3 months after surgery. The mean residual astigmatism (RAS) was $0.91 \pm 0.74 \mathrm{D}$ at 3 months, which was significantly decreased compared with the preoperative corneal astigmatism of $1.71 \pm 0.55 \mathrm{D}$. The mean absolute rotation of TECNIS toric $\mathrm{IOL}$ at 1 and 3 months was $7.42 \pm 11.32$ degree $\left(^{\circ}\right)\left(0-79^{\circ}\right)$ and $7.48 \pm 11.19^{\circ}\left(0-79^{\circ}\right)$, respectively. The mean area of capsulorhexis and the overlapped area between capsulorhexis and IOL optic intraoperatively was $21.04 \pm 3.30 \mathrm{~mm}^{2}$ and $7.40 \pm 2.87 \mathrm{~mm}^{2}$.A positive correlation was found between $\mathrm{IOL}$ rotation and the area of capsulorhexis $(p=$ $0.017)$ at 3 months after surgery. No correlation was found between IOL rotation and AL ( $p=0.876), A C D(p=0.387)$, $\mathrm{LT}(p=0.523), \mathrm{VL}(p=0.546), \mathrm{ACV}(p=0.480)$, STS $(p=0.884), \mathrm{K} 1(p=0.429), \mathrm{K} 2(p=0.644)$, average of $\mathrm{K} 1$ and $\mathrm{K} 2(p=$ 0.520 ), intraoperative IOL axial direction $(p=0.396)$, preoperative corneal astigmatism $(p=0.269)$ or the overlapped area between capsulorhexis and IOL optic intraoperatively $(p=0.131)$.

Conclusions: The large CCC was a risk factor for toric IOL rotation. An appropriately smaller sized CCC was conducive to increase the rotational stability of TECNIS toric IOL implantation in cataract cases with long AL.

Keywords: Astigmatism, Cataract, Toric IOL rotation, Area of capsulorhexis

\footnotetext{
* Correspondence: xuwen2003@zju.edu.cn

${ }^{1}$ Eye Center of the Second Affiliated Hospital, Zhejiang University School of Medicine, No. 88 Jiefang Road, Hangzhou, China

Full list of author information is available at the end of the article
}

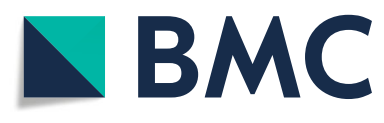

(c) The Author(s). 2020 Open Access This article is licensed under a Creative Commons Attribution 4.0 International License, which permits use, sharing, adaptation, distribution and reproduction in any medium or format, as long as you give appropriate credit to the original author(s) and the source, provide a link to the Creative Commons licence, and indicate if changes were made. The images or other third party material in this article are included in the article's Creative Commons licence, unless indicated otherwise in a credit line to the material. If material is not included in the article's Creative Commons licence and your intended use is not permitted by statutory regulation or exceeds the permitted use, you will need to obtain permission directly from the copyright holder. To view a copy of this licence, visit http://creativecommons.org/licenses/by/4.0/ The Creative Commons Public Domain Dedication waiver (http://creativecommons.org/publicdomain/zero/1.0/) applies to the data made available in this article, unless otherwise stated in a credit line to the data. 


\section{Background}

With the development of phacoemulsification in cataract surgery and design of intraocular lens (IOL), better quality of vision has been achieved postoperatively. Patients with long axial length (AL) who have undergone cataract surgery and had IOL implantation may be willing to decrease myopia and residual astigmatism (RAS). Therefore, the management of pre-existing astigmatism has become more clinically important [1]. There are several surgical options for correcting preoperative astigmatism, such as femtosecond laser-assisted astigmatic keratotomy [2], limbal or corneal relaxing incisions [3],laserassisted in situ keratomileusis (LASIK) [4], and implantation of toric IOLs. Implantation of toric IOL has its superiority of accuracy, predictability and economical efficiency compared with other options. A major problem of toric IOL implantation is the rotational stability. Patients with longer AL accordingly tend to have bigger capsular bags than those with emmetropia or hypermetropia $[5,6]$. It indicates that larger capsular bags may reduce the equatorial friction for a given IOL, and thinner IOL may increase the gap between the optical component and the posterior capsule [7], therefore leading to decreased IOL stability. However, some scholars did not find the correlation between the IOL rotation and AL in myopic eyes [8]. Our previous research has discovered the correlation between toric IOL rotation and LT, AL and area of capsulorhexis in eyes of various axial lengths and a positive correlation between AL and toric IOL rotation [9]. The controversy about the possible correlation between the $\mathrm{AL}$ and $\mathrm{IOL}$ rotation remains furious. In the present study, we focused the toric IOL rotation of cataract patients with long AL eye and aimed to assess the correlation between boimetric measurements and rotational stability of TECNIS toric IOL implantation in cataracts with long AL. Moreover, we attempted to identify the potential factors influencing the rotational stability at early stage after surgery.

\section{Methods}

\section{Study subjects}

A total of 64 eyes that underwent phacoemulsification and implantation of TECNIS toric IOL (AMO Groningen BV, 9728 NX Groningen, the Netherlands) were enrolled in this retrospective non-comparative clinical study. AMO TECNIS toric IOL was a single-piece hydrophobic acrylic aspheric lens with a 6-mm optic diameter and an overall diameter of $13 \mathrm{~mm}$. The IOL had a modified C-loop haptic configuration. The diameter for the outermost and innermost marking holes was $6.1 \mathrm{~mm}$ and $4.6 \mathrm{~mm}$, respectively. All enrolled patients underwent cataract surgery from May, 2015 to October, 2018 at the Eye Center, the Second Affiliated Hospital of Zhejiang University. Informed consent was provided from every participant preoperatively. Before surgery, all patients with cataract had a regular total corneal astigmatism (TCA) of $\geq 1.00 \mathrm{D}$ and an $\mathrm{AL} \geq 25.0 \mathrm{~mm}$. When the difference of the astigmatism meridian of the anterior and posterior surface was within \pm 10 degrees and astigmatism difference was within $\pm 0.75 \mathrm{D}$ and quality safety (QS) was OK, the total astigmatism shown on Pentacam was used to calculate before surgery. Exclusion criteria included patients with following eye conditions, such as irregular corneal astigmatism, a history of intraocular surgery, pterygium, glaucoma, retinal detachment, uveitis, macular degeneration or retinopathy, lens subluxation, posterior capsule opacification, and abnormal lens morphology. The refractive target of sphere was low myopia or emmetropia.

\section{Preoperative examinations}

Long AL was defined as an AL of $25 \mathrm{~mm}$ or greater. Preoperatively, patients had a routine examination for uncorrected distance visual acuity (UCDVA), best corrected distance visual acuity (BCDVA), intraocular pressure (IOP), manifest refraction, slit-lamp examination with pupillary dilation, biometric measurement and toric IOL calculations. The biometric measurement included AL (IOLMaster 500, Carl Zeiss, Advanced Technology V.5.5, Germany), TCA (Pentacam; Oculus Optikgeräte $\mathrm{GmbH}$, Wetzlar, Germany), keratometry (K) and anterior chamber volume (ACV) (Pentacam; Oculus Optikgeräte $\mathrm{GmbH}$, Wetzlar, Germany), anterior chamber depth (ACD) (Pentacam; Oculus Optikgeräte GmbH, Wetzlar, Germany) and sulcus-to-sulcus (STS) (Anterior Segment VisanteTM OCT, Carl Zeiss, Germany). Immersion A-scan biometry (Quantel Medical CineScan AVISO, France) was used to determine the lens thickness (LT) and vitreous length (VL). The spherical power of IOL was examined using SRK-T formula, and the cylinder power and alignment axis were calculated using an online calculator (https://www.TecnisToricCalc.com). Surgically induced astigmatism (SIA) was entered as 0.3 $\mathrm{D}$ with a $2.0-\mathrm{mm}$ clear limbal incision, and TCA was taken into account for calculation of the IOL's cylindrical power. The steep meridian of the corneal was used to determine the incision position.

\section{Surgical technique}

Each patient underwent the same technique by an experienced surgeon (Dr. Wen $\mathrm{Xu})$. With the patients sitting upright on a slit-lamp microscope, the 0 and 180 degree positions of the corneal limbus were precisely marked with a fine syringe needle and highlighted with skin marker (Medplus Inc.) before pupil was dilated by a same skillful assistant. After topical or general anesthesia, toric IOL alignment axis was marked using a Mendez ring and highlighted for recognition under the 
operating microscope. Generally toric IOL alignment axis was marked on the steep meridian of cornea. A $2.0-\mathrm{mm}$ clear limbal incision was made on the steep meridian with central continuous curvilinear capsulorhexis (CCC) followed by phacoemulsification and cortical aspiration. The toric IOL was inserted into the capsular bag using an injector (DK7786 with One Series Ultra Cartridge Implantation System) and rotated into a position approximately $5^{\circ}$ to $10^{\circ}$ counter-clock wise from the planned axis. After all the viscoelastic substances were removed from behind and in front of the IOL, the axis was aligned in a clockwise direction to the intended placement. The incisions were hydrated, and the position of the IOL was properly oriented prior to the end of surgery. No sutures were used to close the wound. For analysis of Toric IOL axis, the area of capsulorhexis and the overlapped area between capsulorhexis and IOL optic, the procedures of all surgeries were recorded. The postoperative treatment consisted of prednisolone acetate eye drops (Allergan Pharmaceutical Ireland, Westport, Ireland) and levofloxacin (Cravit, Santen Pharmaceutical) four times a day for 7 days, as well as pranprofen (Pranopulin, Senju Pharmaceutical, Osaka, Japan) and sodium hyaluronate eye drops (URSAPHARM Arzneimittel GmbH, Germany) four times a day for 1 month.

\section{Postoperative examinations}

Postoperatively, patients received examinations at 1 week, 1 month and 3 months. Postoperative 1 - and 3-

Table 1 Patient characteristics before the cataract surgery

\begin{tabular}{ll}
\hline Parameters & Value \\
\hline Age (years) & $59.17 \pm 17.14(17-83)$ \\
Gender (male/female) & $22 / 30$ \\
Operate eye (right/left) & $35 / 29$ \\
BCDVA (LogMAR) & $0.93 \pm 0.35(1.7-0.2)$ \\
AL (mm) & $27.15 \pm 1.48(25.0-31.38)$ \\
ACD (mm) & $2.85 \pm 0.27(2.42-3.48)$ \\
LT (mm) & $4.70 \pm 0.78(3.48-6.42)$ \\
VL (mm) & $19.36 \pm 1.59(15.76-23.44)$ \\
STS (mm) & $11.95 \pm 0.79(10.28-13.94)$ \\
ACV (mm ${ }^{3}$ ) & $150.69 \pm 30.58(107-225)$ \\
Corneal astigmatism (D) & $1.71 \pm 0.55(1.0-3.7)$ \\
Toric IOL axis (degree) & $80.82 \pm 51.13(0-179)$ \\
Spherical power of IOL (D) & $15.20 \pm 3.40(5.5-20)$ \\
K1(D) & $42.51 \pm 1.69(37.8-46.7)$ \\
K2(D) & $44.22 \pm 1.61(40.9-48.3)$ \\
Average keratometric value (D) & $43.36 \pm 1.63(39.65-47.25)$ \\
\hline BCDVA best corected distance visual &
\end{tabular}

$B C D V A$ best corrected distance visual acuity, logMAR logarithms of the minimal angle of resolution, $A L$ axial length, $A C D$ anterior chamber depth, $L T$ lens thickness, VL vitreous length; STS sulcus-to-sulcus, $A C V$ anterior chamber volume, $D$ diopter, $I O L$ intraocular lens, $K 1$ flat meridian of keratometric value, $K 2$ steep meridian of keratometric value
Table 2 TECNIS toric intraocular lens model

\begin{tabular}{ll}
\hline Intraocular lens model & N (\%) \\
\hline ZCT100 & $4(6.25)$ \\
ZCT150 & $27(42.18)$ \\
ZCT225 & $20(31.25)$ \\
ZCT300 & $8(12.50)$ \\
ZCT400 & $5(7.81)$ \\
\hline
\end{tabular}

month follow-ups included slit-lamp examination, intraocular pressure, BCDVA, manifest refraction and digital anterior segment photography. Pupil was adequately dilated to visualize the toric axis marks and the edge of capsulorhexis with a mixture of phenylephrine and 0.5\% tropicamide (Mydrin-P; Santen Pharmaceutical). The patients seated before slit-lamp microscope (TOPCON SLD701, Japan) with an upright position, and digital anterior segment photographs (Topcon, Tokyo, Japan) were acquired and recorded. A conjunctive blood vessel or pigment was selected as a reference meridian to eliminate the influence of head tilt or eye rotation. The difference of IOL axial direction between intraoperative actual axis and postoperative alignment, the area of capsulorhexis and the overlapped area between capsulorhexis and IOL optic were calculated using the ruler tool of Rhinoceros 5.0 (Robert McNeel \& Assoc, America) for three times. The mean value was selected for statistical analysis.

\section{Statistical analysis}

All statistical analyses were performed using SPSS Statistics 17.0 (SPSS, Chicago, Illinois, USA). Continuous variables were expressed as the mean and standard deviation (SD). The correlations between continuous variables were assessed using Pearson's correlation analysis. Multiple linear regression analysis was then performed to assess the independent effects of the various factors that might be associated with toric IOL rotation. A probability value of less than 0.05 was considered statistically significant.

Table 3 Residual astigmatism 3 months after toric IOL implantation

\begin{tabular}{ll}
\hline Residual astigmatism $(\mathrm{D})$ & $\mathrm{N}(\%)$ \\
\hline$\leq-0.50$ & $22(34.37)$ \\
$-0.51 \mathrm{D}$ to-1.00 & $25(39.06)$ \\
$-1.01 \mathrm{D}$ to- 1.50 & $12(18.75)$ \\
$1.51 \mathrm{D}$ to -2.00 & $2(3.12)$ \\
$>-2.00$ & $3(4.68)$
\end{tabular}

$\mathrm{IOL}$ intraocular lens, $D$ diopter 


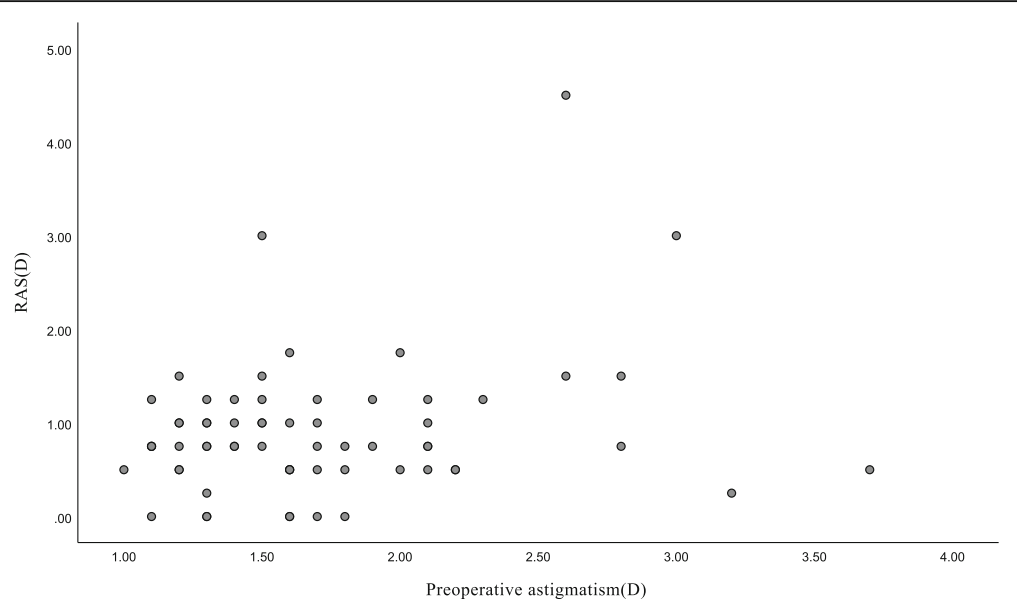

Fig. 1 The distribution of the preoperative astigmatism and RAS. No significant correlation was observed between RAS and the preoperative astigmatism (Pearson's $r=0.243, p=0.053$ ). RAS residual astigmatism

\section{Results}

\section{Preoperative characteristics}

A total of 64 eyes from 52 patients, including 35 right and 29 left eyes, were enrolled in the present study. The mean age of patients at the time of surgery was $59.17 \pm$ 17.14 years, ranging from 17 to 83 years. The mean preoperative BCDVA was $0.93 \pm 0.35 \log$ MAR. Table 1 shows the statistical characteristics of patients before the cataract surgery. Table 2 lists the TECNIS toric IOL models.

\section{Postoperative visual acuity and refraction}

BCDVA was significantly improved from $0.93 \pm 0.35$ logMAR to $0.07 \pm 0.10 \log$ MAR after surgery at 3 months postoperatively. The RAS was $1.11 \pm 0.75 \mathrm{D}$ and $0.91 \pm$ $0.74 \mathrm{D}$ at 1 month and 3 months after surgery, respectively. There was significant difference in RAS between 1 and 3 months $(p<0.001)$. RAS was controlled within $0.50 \mathrm{D}$ in $34.37 \%(22 / 64)$ and $-1.00 \mathrm{D}$ in $73.43 \%(47 / 64)$ of patients at 3 months. Table 3 shows RAS at 3 months after implantation of toric IOL. Figure 1 shows the distribution of the preoperative astigmatism and RAS. The proportion of patients with high astigmatism preoperatively among large RAS was $28.57 \%$ (2/7). Table 4 lists the distribution of preoperative astigmatism among large RAS.

\section{State of toric IOL rotation}

The mean toric IOL rotation was $7.42 \pm 11.32^{\circ}\left(0^{\circ}-79^{\circ}\right)$ and $7.48 \pm 11.19^{\circ}\left(0^{\circ}-79^{\circ}\right)$ at 1 and 3 months after surgery, respectively. The intraoperative mean area of capsulorhexis was $21.04 \pm 3.30 \mathrm{~mm}^{2}$ for evaluating the correlation between the IOL rotation and the area of capsulorhexis. The mean area of capsulorhexis and the overlapped area between capsulorhexis and IOL optic was $21.00 \pm 3.34 \mathrm{~mm}^{2}$ and $7.36 \pm 2.82 \mathrm{~mm}^{2}$ at 1 month and $20.52 \pm 3.31 \mathrm{~mm}^{2}$ and $7.34 \pm 2.81 \mathrm{~mm}^{2}$ at 3 months postoperatively. The results indicated that $54.68 \%$ (35/ 64) patients were within $5^{\circ}$ absolute rotation, and RAS within $-0.50 \mathrm{D}$ and $-1.00 \mathrm{D}$ was $34.37 \%(22 / 64)$ and $73.43 \%(47 / 64)$ at 3 -month follow-up, respectively. Table 5 shows the IOL misalignment after toric IOL implantation.

There were four eyes rotated more than $15^{\circ}$, and the greatest rotation reached $79^{\circ}$. In these four cases with significant rotation in our study, the $\mathrm{AL}$ ranged from $26.20 \mathrm{~mm}$ to $27.57 \mathrm{~mm}$, and the corneal astigmatism ranged from $1.3 \mathrm{D}$ to $3.0 \mathrm{D}$. The axis alignment of these cases was $158^{\circ}, 88^{\circ}, 92^{\circ}$ and $81^{\circ}$ intraoperatively and rotated $16^{\circ}, 33^{\circ}, 40^{\circ}$ and $79^{\circ}$ at 3 months after surgery, respectively. Table 6 lists the characteristics of four cases with large rotation.

\section{Factors associated with toric IOL rotation}

The mean area of capsulorhexis was $21.04 \pm 3.30 \mathrm{~mm}^{2}$, ranging from 14.45 to $31.16 \mathrm{~mm}^{2}$ intraoperatively. Toric IOL rotation was positively correlated with the intraoperative area of capsulorhexis $(y=1.008 x-13.724$, Pearson's $r=$ 0.297, $p=0.017$ ) (Fig. 2). The variables included in the

Table 4 RAS according to the preoperative astigmatism

\begin{tabular}{ll}
\hline Preoperative astigmatism (D) & RAS (D) \\
\hline 2.6 & 1.5 \\
2.6 & 4.5 \\
2.8 & 0.75 \\
2.8 & 1.5 \\
3 & 3 \\
3.2 & 0.25 \\
3.7 & 0.5 \\
\hline
\end{tabular}

The proportion of patients with high astigmatism ( $>2.5 \mathrm{D})$ preoperatively among large RAS was $28.57 \%$ (2/7). RAS residual astigmatism; D diopter 
Table 5 Intraocular lens misalignment after toric IOL implantation

\begin{tabular}{llll}
\hline IOL rotation (degrees) & 3 Months N (\%) & clockwise N (\%) & Counter-clockwise N (\%) \\
\hline$\leq 5$ & $35(54.68)$ & $16(25.00)$ & $16(25.00)$ \\
$>5$ and $\leq 10$ & $21(32.81)$ & $9(14.06)$ & $12(18.75)$ \\
$>10$ and $\leq 15$ & $4(6.25)$ & $2(3.12)$ & $2(3.12)$ \\
$>15$ & $4(6.25)$ & $3(4.68)$ & $1(1.56)$ \\
\hline
\end{tabular}

$\mathrm{IOL}$ intraocular lens

multiple linear regression analysis were age, gender, operated eye, preoperative BCDVA, preoperative total corneal astigmatism, AL, ACD, LT, VL, ACV, STS, keratometric value, spherical power of the implanted IOLs, intraoperative actual IOL axial direction, preoperative corneal astigmatism, the intraoperative area of capsulorhexis and the overlapped area between capsulorhexis and IOL optic. Table 7 shows the correlation analysis of toric IOL rotation as the dependent variable.

\section{Discussion}

Astigmatism with long $\mathrm{AL}$ is the common refractive error of patients with cataract. Toshiyuki Miyake et al. have studied the distribution of corneal astigmatism in 12,428 eyes after cataract surgery and reported that $36.3 \%$ of eyes have more than $1.0 \mathrm{D}$ of corneal astigmatism, $8.0 \%$ have more than $2.0 \mathrm{D}$, and $2.4 \%$ have more than 3.0 D [10]. Postoperative misalignment is a significant problem in toric IOL implantation. Therefore, we observed the clinical outcomes and evaluated rotational stability and its possible related factors, including preoperative biometric examinations and surgical operation.

In our retrospective study, the mean RAS and absolute IOL rotation were $0.91 \pm 0.74 \mathrm{D}$, ranging from 0 to- $4.5 \mathrm{D}$, and $7.48 \pm 11.19^{\circ}\left(0-79^{\circ}\right)$ at 3 months after surgery, respectively, which were larger than those in the eyes with various axial length in other studies $[5,11]$. This might be attributed to the fact that all patients had long AL or a higher percentage of high myopia. No significant differences were observed in toric IOL rotation between 1 and 3 months, suggesting that toric IOL rotation mainly occurred within 1 month after surgery [12]. Compared with toric IOL implantation in eyes of emmetropia, hyperopia or AL shorter than $25 \mathrm{~mm}$ of other studies [13-16], the higher rate of IOL rotation would occur in patients with long AL probably.

We established that Toric IOL rotation was positively correlated with the area of capsulorhexis $(y=1.008 x$ 13.724, Pearson's $r=0.297, p=0.017$ ), while there was no correlation with the overlapped area between capsulorhexis and IOL optic. These findings suggested that an

Table 6 Characteristics of 4 large rotation cases $\left(>15^{\circ}\right)$

\begin{tabular}{|c|c|c|c|c|}
\hline Parameters & Case 1 & Case2 & Case3 & Case4 \\
\hline $\mathrm{ACD}(\mathrm{mm})$ & 2.67 & 2.63 & 2.71 & 2.77 \\
\hline ACV $(\mathrm{mm} 3)$ & 127 & 122 & 110 & 161 \\
\hline $\mathrm{LT}(\mathrm{mm})$ & 4.4 & 6.15 & 4.34 & 4.51 \\
\hline $\mathrm{VL}(\mathrm{mm})$ & 19.55 & 19.58 & 18.32 & 18.88 \\
\hline $\mathrm{AL}(\mathrm{mm})$ & 27.34 & 26.78 & 26.2 & 26.96 \\
\hline Preoperative total corneal astigmatism (D) & 1.3 & 3 & 2.6 & 1.5 \\
\hline Spherical power of IOL (D) & 15 & 15 & 13 & 17 \\
\hline Toric IOL models & ZCT150 & ZCT400 & ZСТ300 & ZCT225 \\
\hline Intraoperative IOL axis (degree) & 158 & 88 & 92 & 81 \\
\hline Area of capsulorhexis (mm2) & 17.8 & 21.37 & 18.83 & 31.16 \\
\hline Area of overlap between capsulorhexis and optic (mm2) & 10.46 & 6.89 & 9.43 & 1.58 \\
\hline K1(D) & 44.4 & 43.4 & 43.2 & 40.4 \\
\hline K2(D) & 45.7 & 46.4 & 45.8 & 41.9 \\
\hline Absolute value of rotation 1 month postoperatively (dgree) & 16 & 33 & 40 & 79 \\
\hline Absolute value of rotation 3 months postoperatively (dgree) & 16 & 33 & 40 & 79 \\
\hline
\end{tabular}

In Case4, the area of capsulorhexis was largest (31.16 mm2), the area of overlap between capsulorhexis and optic was smallest (1.58 mm2). As a result, the toric $\mathrm{IOL}$ rotation reached $79^{\circ}$ at 3 months after surgery

$A C D$ anterior chamber depth, $A C V$ anterior chamber volume, $L T$ lens thickness, $V L$ vitreous length, $A L$ axial length, $D$ diopter, $I O L$ intraocular lens 


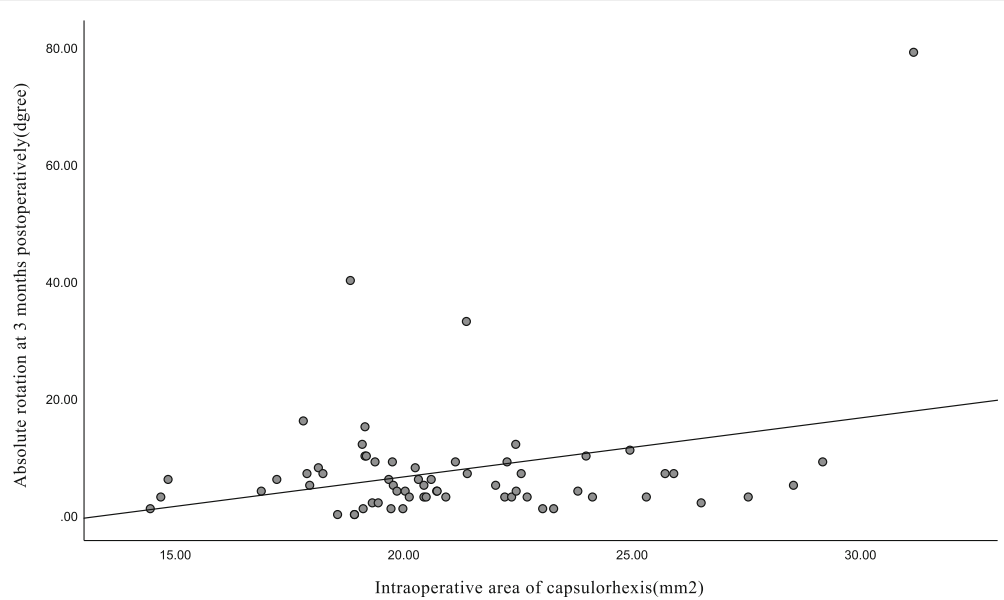

Fig. 2 The correlation between Toric rotation and the area of capsulorhexis was assessed using Pearson's correlation analysis. Toric IOL rotation was positively correlated with the area of capsulorhexis (Pearson's $r=0.297, p=0.017$ ). $10 \mathrm{~L}$ intraocular lens

appropriately sized CCC was essential to prevent IOL rotation, especially at early stage after surgery. A relatively smaller sized CCC was conducive than oversize one. There were significant negative correlations between the area of CCC and the overlapped area between capsulorhexis and IOL optic $(p<0.001, r=-0.979)$. Moreover, we didn't find a correlation between IOL rotation and AL, LT, VL, ACD, STS, keratometry value, the spherical power of the implanted IOL.

Four cases in our study rotated more than $15^{\circ}$. There were no significant differences between the four cases and other cases in terms of average ACD, ACV, LT, AL, the

Table 7 Correlation between toric IOL rotation and the dependent variables

\begin{tabular}{lll}
\hline Variables & Pearson's r & $P$ Value \\
\hline AL & -0.02 & 0.876 \\
ACD & -0.113 & 0.387 \\
LT & 0.083 & 0.523 \\
VL & -0.082 & 0.546 \\
STS & 0.019 & 0.884 \\
ACV & -0.094 & 0.48 \\
Keratometry K1 & -0.101 & 0.429 \\
Keratometry K2 & -0.059 & 0.644 \\
Intraopertive IOL axial direction & 0.396 & 0.108 \\
Preoperative corneal astigmatism & 0.14 & 0.269 \\
Area of capsulorhexis & 0.297 & $0.017^{*}$ \\
Area of overlap between capsulorhexis and optic & -0.191 & 0.131 \\
Spherical power of IOLs & 0.02 & 0.872 \\
\hline
\end{tabular}

*Statistically significant correlation $(p<0.05)$

Toric IOL rotation was positively correlated with the area of capsulorhexis (Pearson's $r=0.297, p=0.017$ )

$I O L$ intraocular lens, $A L$ axial length, $A C D$ anterior chamber depth, $L T$ lens thickness, $V L$ vitreous length, STS sulcus-to-sulcus, $A C V$ anterior chamber volume, $K 1$ flat meridian of keratometric value, $K 2$ steep meridian of keratometric value intraoperative area of $\mathrm{CCC}$, and the area of overlap between capsulorhexis and IOL optic. Among the data, the case in which toric IOL rotation reached $79^{\circ}$ at 3 months after surgery had a significantly larger intraoperative area of capsulorhexis than the average of others. The capsulorhexis size was too large to fix the toric IOL, and the edge of IOL was almost free, therefore leading to IOL rotated extensively (Fig. 3). It was observed in the two cases which rotated $33^{\circ}$ and $40^{\circ}$ without too large capsulorhexis size, including larger preoperative corneal astigmatism, intraoperative approximately vertical toric IOL alignment. No correlations were found between IOL rotation and the variables, including keratometric value, intraoperative IOL axial direction, preoperative corneal astigmatism. Therefore, accumulation of more cases and a long-term observation should be taken in future.

During the first 3 months after surgery, several studies have mentioned that the toric IOL rotation can be attributed to an IOL surface with a low coefficient of friction [17], thinner optic of low-powered IOLs [10], the design of the IOL [18], an overall length of the IOL that is too small for the capsular bag [19] and instability of the anterior chamber [20].

Some earlier studies have found a positive correlation between early rotation of the toric IOL and $\mathrm{AL}$, which is positively correlated with the diameter of the capsular bag [21-23]. Since the diameter of capsular bag cannot be measured directly, we measured STS using Anterior Segment Visante ${ }^{\mathrm{Tm}}$ OCT, which is a non-contact optical signal acquisition. We didn't find a correlation between AL and STS (Pearson's $r=-0.005, p=0.971$ ), suggesting that AL was not positively correlated with the diameter of the capsular bag in a long AL eye.

Other earlier literature has also indicated that the area of CCC was contractible at 3 months compared with 1 month after surgery. When the collapses and fibroses of 


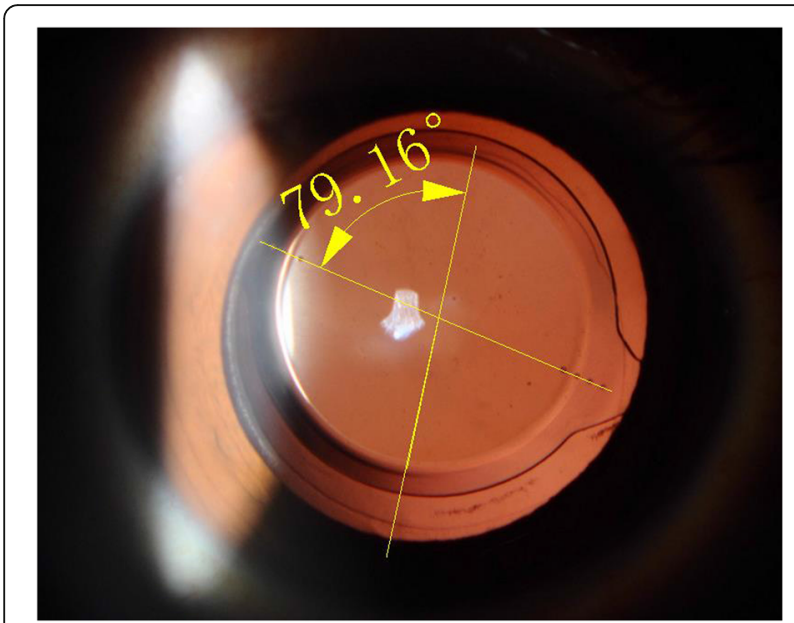

Fig. 3 Photograph showed the rotation of Case 4 by Rhinoceros 5.0. The edge of $\mathrm{IOL}$ was almost free and it rotated $79^{\circ}$ at 3 months after surgery. IOL intraocular lens

capsular bag occur, the area of CCC would decrease and influenced the IOL rotation stability [24]. In our observation, compared with intraoperative one, the area of CCC was decreased slightly at 1 month postoperatively and continued to be decreased at 3 months postoperatively. Meanwhile, the axis of implanted toric IOL was not changed in the 3-month follow-up.

There are some limitations in our study. The digital anterior segment photographs were used to calculate the area of capsulorhexis as well as the overlapped area between capsulorhexis and IOL optic. This process was related with the subjectivity of the operator. In order to reduce the influence of inaccurate calculation, we repeated the measurement for three times. The toric IOL alignment axis marker was at $10^{\circ}$ intervals, and manual marking was used. VERION system has the advantage of intraoperative digital guidance of the toric IOL alignment even for $1^{\circ}$ [25]. It has been reported that the underlying capsular shrinking probably occurs at 6 months or 1 year after cataract surgery, with the beginning in the first 3 months [26]. In order to reduce the postoperative RAS seized with SIA, we evaluated the early-stage outcomes until 3 months after the surgery in this study. Inevitably, some cases might already suffer from a very early-stage fibrosis and contraction of the capsular bag at this time.

Our data showed the refractive results and the factors influencing toric IOL rotation in eyes with long AL. The area of CCC affected their early-stage stability of toric IOL axis after surgery. However, the long-term influence from the capsular bag contraction and posterior capsular opacity should be considered.

\section{Conclusions}

Over all, the large CCC was a risk factor for toric IOL rotation in eyes with long AL. An appropriately smaller sized CCC was conducive to increase the rotational stability rather than an oversize one.

\section{Supplementary information}

Supplementary information accompanies this paper at https://doi.org/10. 1186/s12886-020-01465-2.

Additional file 1. Data for statistic analysis.

\begin{abstract}
Abbreviations
IOL: Intraocular lens; AL: Axial length; D: Diopter; ACD: Anterior chamber depth; LT: Lens thickness; VL: Vitreous length; ACV: Anterior chamber volume; STS: Sulcus-to-sulcus; K: Keratometric value;; BCDVA: Best corrected distance visual acuity; logMAR: Logarithms of the minimal angle of resolution; RAS: Residual astigmatism degree; LASIK: Laser-assisted in situ keratomileusis; TCA: Total corneal astigmatism; QS: Quality safety; UCDVA: Uncorrected distance visual acuity; OCT: Optical coherence tomography; SIA: Surgically induced astigmatism; CCC: Continuous curvilinear capsulorhexis; SD: Standard deviation
\end{abstract}

\section{Acknowledgements}

We thank PhD. Jianfeng Luo for the help of analysis of data who is from Department of Biostatistics School of Public Health Fudan University, Shanghai, China.

\section{Authors' contributions}

All authors conceived of and designed the study. All authors were involved in the data analysis. HSH did the patients follow-up, collected data and drafted the article. WXD and MYJ reviewed the literature. CX and YXW revised the manuscript. XW did the surgery and drafted the article. All authors reviewed the manuscript and approved the final manuscript.

\section{Funding}

This work was supported by the Key Research and Development Plan of Zhejiang Province Science and Technology Hall (2017C03046). The funding bodies had no role in the design of the study and collection, analysis, and interpretation of data and in the writing of the manuscript.

\section{Availability of data and materials}

The datasets used and/or analyzed during the current study are available from the corresponding author on reasonable request.

\section{Ethics approval and consent to participate}

This research article was approved by the ethics committee of the second Affiliated Hospital, Zhejiang University School of Medicine, and the research followed the tenets of the Declaration of Helsinki. Written consent was obtained from all patients.

\section{Consent for publication}

Not applicable.

\section{Competing interests}

The authors declare that they have no competing interests.

\section{Author details}

${ }^{1}$ Eye Center of the Second Affiliated Hospital, Zhejiang University School of Medicine, No. 88 Jiefang Road, Hangzhou, China. ${ }^{2}$ Suichang Hospital of Traditional Chinese Medicine, Suichang, China. 
Received: 20 April 2019 Accepted: 6 May 2020

Published online: 25 May 2020

\section{References}

1. Bandeira F, Morral M, Elies D, Eguiza S, Souki S, Manero F, et al. Transitional conic toric intraocular lens for the management of corneal astigmatism in cataract surgery. Clin Ophthalmol. 2018;12:1071-9.

2. Wang J, Zhao J, Xu J, Zhang J. Evaluation of the effectiveness of combined femtosecond laser-assisted cataract surgery and femtosecond laser astigmatic keratotomy in improving post-operative visual outcomes. BMC Ophthalmol. 2018:18(1):161.

3. Monaco G, Scialdone A. Long-term outcomes of limbal relaxing incisions during cataract surgery: aberrometric analysis. Clin Ophthalmol. 2015;9: $1581-7$.

4. Mohammad-Rabei H, Mohammad-Rabei E, Espandar G, Javadi MA Jafarinasab MR, Hashemian SJ, et al. Three methods for correction of astigmatism during phacoemulsification. J Ophthalmic Vis Res. 2016;11(2): $162-7$.

5. Zhu X, He W, Zhang K, Lu Y. Factors influencing 1-year rotational stability of AcrySofToric intraocular lenses. Br J Ophthalmol. 2016;100(2):263-8.

6. Vass C, Menapace R, Schmetterer K, Findl O, Rainer G, Steineck I. Prediction of pseudophakic capsular bag diameter based on biometric variables. J Cataract Refract Surg. 1999;25(10):1376-81.

7. Khan Ml, Ch'ng SW, Muhtaseb M. The use of toric intraocular lens to correct astigmatism at the time of cataract surgery. Oman J Ophthalmol. 2015;8(1): 38-43.

8. Mencucci R, Favuzza E, Guerra F, Giacomelli G, Menchini U. Clinical outcomes and rotational stability of a 4-haptic toric intraocular lens in myopic eyes. J Cataract Refract Surg. 2014;40(9):1479-87.

9. Li S, Li X, He S, Zheng Q, Chen X, Wu X, et al. Early postoperative rotational stability and its related factors of a single-piece acrylic toric intraocular lens. Eye (Lond). 2019;34(3):474.

10. Miyake T, Kamiya K, Amano R, lida Y, Tsunehiro S, Shimizu K. Long-term clinical outcomes of toric intraocular lens implantation in cataract cases with preexisting astigmatism. J Cataract Refract Surg. 2014;40(10):1654-60.

11. Jung NY, Lim DH, Hwang SS, Hyun J, Chung TY. Comparison of clinical outcomes of toric intraocular lens, Precizon vs Tecnis: a single center randomized controlled trial. BMC Ophthalmol. 2018;18(1):292.

12. Correia RJ, Moreira H, Netto SU, Pantaleao GR. Visual performance after toric IOL implantation in patients with corneal astigmatism. Arq Bras Oftalmol. 2009:72(5):636-40.

13. Nakano Y, Nomoto H, Fukuda K, Yamaji H, Fujita T, Inoue Y, et al. Combined 25-gauge vitrectomy and cataract surgery with toric intraocular lens with idiopathic epiretinal membrane. J Cataract Refract Surg. 2013;39(5):686-93.

14. Waltz KL, Featherstone K, Tsai L, Trentacost D. Clinical outcomes of TECNIS toric intraocular lens implantation after cataract removal in patients with corneal astigmatism. Ophthalmology. 2015;122(1):39-47.

15. Hirnschall N, Maedel S, Weber M, Findl O. Rotational stability of a singlepiece toric acrylic intraocular lens: a pilot study. Am J Ophthalmol. 2014; 157(2):405-11 e401.

16. Grohlich M, Mihaltz K, Lasta M, Weingessel B. Vecsei-Marlovits V: [evaluation of postoperative astigmatism correction and postoperative rotational stability of two Toric intraocular lenses]. KlinMonblAugenheilkd. 2017;234(6): 796-804.

17. Vandekerckhove K. Rotational stability of Monofocal and trifocal intraocular Toric lenses with identical design and material but different surface treatment. J Refract Surg. 2018;34(2):84-91.

18. Chang DF. Comparative rotational stability of single-piece open-loop acrylic and plate-haptic silicone toric intraocular lenses. J Cataract Refract Surg. 2008;34(11):1842-7.

19. Novis C. Astigmatism and toric intraocular lenses. CurrOpinOphthalmol. 2000;11(1):47-50.

20. Edrington TB. A literature review: the impact of rotational stabilization methods on toric soft contact lens performance. Cont Lens Anterior Eye. 2011:34(3):104-10.

21. Shah GD, Praveen MR, Vasavada AR, Vasavada VA, Rampal G, Shastry LR. Rotational stability of a toric intraocular lens: influence of axial length and alignment in the capsular bag. J Cataract Refract Surg. 2012;38(1):54-9.

22. Vasavada A, Singh R. Relationship between lens and capsular bag size. J Cataract Refract Surg. 1998;24(4):547-51.
23. Zhu X, Lu Y. Detection and influencing factors of capsular bag distention syndrome after cataract surgery using the PentacamScheimpflug system. Am J Ophthalmol. 2013;156(6):1134-40 e1134.

24. Boyce JF, Bhermi GS, Spalton DJ, El-Osta AR. Mathematical modeling of the forces between an intraocular lens and the capsule. J Cataract Refract Surg. 2002;28(10):1853-9.

25. Elhofi AH, Helaly HA. Comparison between digital and manual marking for Toric intraocular lenses: a randomized trial. Medicine (Baltimore). 2015; 94(38):e1618.

26. Ruhswurm I, Scholz U, Zehetmayer M, Hanselmayer G, Vass C, Skorpik C. Astigmatism correction with a foldable toric intraocular lens in cataract patients. J Cataract Refract Surg. 2000;26(7):1022-7.

\section{Publisher's Note}

Springer Nature remains neutral with regard to jurisdictional claims in published maps and institutional affiliations.

\section{Ready to submit your research? Choose BMC and benefit from:}

- fast, convenient online submission

- thorough peer review by experienced researchers in your field

- rapid publication on acceptance

- support for research data, including large and complex data types

- gold Open Access which fosters wider collaboration and increased citations

- maximum visibility for your research: over $100 \mathrm{M}$ website views per year

At BMC, research is always in progress.

Learn more biomedcentral.com/submissions 